\title{
Trypanocidal Activity of Smallanthus sonchifolius: Identification of Active Sesquiterpene Lactones by Bioassay-Guided Fractionation
}

\author{
F. M. Frank, ${ }^{1}$ J. Ulloa, ${ }^{2}$ S. I. Cazorla, ${ }^{1}$ G. Maravilla, ${ }^{2}$ E. L. Malchiodi, ${ }^{1}$ A. Grau, ${ }^{3}$ V. Martino, ${ }^{2}$ \\ C. Catalán, ${ }^{4}$ and L. V. Muschietti ${ }^{2}$ \\ ${ }^{1}$ Cátedra de Inmunología, IDEHU (UBA-CONICET), Facultad de Farmacia y Bioquímica Junín 956, 1113, Buenos Aires, \\ Argentina, Instituto de Microbiología y Parasitología Médica, IMPaM (UBA-CONICET), Facultad de Medicina, Paraguay 215, \\ 1121 Buenos Aires, Argentina \\ ${ }^{2}$ Cátedra de Farmacognosia, (IQUIMEFA) (UBA-CONICET), Facultad de Farmacia y Bioquímica, Junín 956, \\ 1113 Buenos Aires, Argentina \\ ${ }^{3}$ Instituto de Ecología Regional (IER), Facultad de Ciencias Naturales, Universidad Nacional de Tucumán, \\ 4107 Yerba Buena, Tucumán, Argentina \\ ${ }^{4}$ INQUINOA (CONICET), Facultad de Bioquímica, Química y Farmacia, UNT, Ayacucho 471, \\ 4000 San Miguel de Tucumán, Argentina
}

Correspondence should be addressed to F. M. Frank; ferfrank@ffyb.uba.ar

Received 8 April 2013; Accepted 15 May 2013

Academic Editor: Valdir Cechinel Filho

Copyright ( $\odot 2013$ F. M. Frank et al. This is an open access article distributed under the Creative Commons Attribution License, which permits unrestricted use, distribution, and reproduction in any medium, provided the original work is properly cited.

In order to find novel plant-derived biologically active compounds against Trypanosoma cruzi, we isolated, from the organic extract of Smallanthus sonchifolius, the sesquiterpene lactones enhydrin (1), uvedalin (2), and polymatin B (3) by bioassay-guided fractionation technique. These compounds showed a significant trypanocidal activity against the epimastigote forms of the parasite with $\mathrm{IC}_{50}$ values of $0.84 \mu \mathrm{M}(1), 1.09 \mu \mathrm{M}(2)$, and $4.90 \mu \mathrm{M}$ (3). After a $24 \mathrm{~h}$ treatment with $10 \mu \mathrm{g} / \mathrm{mL}$ of enhydrin or uvedalin, parasites were not able to recover their replication rate. Compounds 1 and 2 showed $\mathrm{IC}_{50}$ values of $33.4 \mu \mathrm{M}$ and $25.0 \mu \mathrm{M}$ against $T$. cruzi trypomastigotes, while polymatin $\mathrm{B}$ was not active. When the three compounds were tested against the intracellular forms of $T$. cruzi, they were able to inhibit the amastigote replication with $\mathrm{IC}_{50}$ of $5.17 \mu \mathrm{M}, 3.34 \mu \mathrm{M}$, and $9.02 \mu \mathrm{M}$ for $\mathbf{1}, \mathbf{2}$, and 3, respectively. The cytotoxicity of the compounds was evaluated in Vero cells obtaining $\mathrm{CC}_{50}$ values of $46.5 \mu \mathrm{M}(\mathbf{1}), 46.8 \mu \mathrm{M}(2)$, and $147.3 \mu \mathrm{M}$ (3) and the selectivity index calculated. According to these results, enhydrin and uvedalin might have potentials as agents against Chagas disease and could serve as lead molecules to develop new drugs.

\section{Introduction}

Chagas disease, also called American trypanosomiasis is an endemic disease that remains as a major public health problem in Latin America. It is estimated that approximately 10 million people are infected and 100 million are at risk worldwide, mainly due to population migrations. The disease is caused by a kinetoplastid protozoan parasite, Trypanosoma cruzi, which is primarily transmitted by blood-sucking insects widely known in endemic countries as "kissing bugs." The acute clinical stage of the disease (in which $5 \%$ of children die) is characterized by fever, generalized lymphadenopathy, and hepatosplenomegaly. The chronic stage often involves mainly cardiac and/or digestive disturbances being a leading cause of infectious cardiomyopathy worldwide [1].

Current treatments are based on the nitro-derivatives benznidazole and nifurtimox, two drugs developed more than four decades ago. They are employed in acute and early chronic cases. However, these drugs have an unsatisfactory cure rate in the chronic disease, are frequently not well tolerated, and cause toxic side effects [2]. Hence, improved treatment options are needed for all stages of T. cruzi infection. 
Medicinal plants produce a variety of chemical compounds and are still a major source of innovative therapeutic agents for various diseases, directly in their native form, or more often after optimization by structural modifications or by the synthesis of analogs with improved pharmacological properties [3]. Many reports concerning the antiprotozoal activity of natural compounds from plant origin have been reported [4-9].

Smallanthus sonchifolius (Asteraceae), a herbaceous perennial plant native to South America, is locally known as "yacon," "llacuma," and "jiquima" or "poire de terre" and "yacon strawberry" in Europe. The history of yacon goes far back beyond the Incas. This plant originates from the Andean region, whence it has spread to New Zealand, Japan, and Brazil. It is grown throughout the Andes, from Colombia to Northwestern Argentina [10, 11], and its cultivation and consumption have expanded in recent decades to several Asian and European countries [12]. Yacon has been identified as a traditional food in the Andean region, and it is also used as an offering during religious festivities [11]. Besides from its use as food, yacon is also acknowledged as a medicinal plant. Antidiabetic properties have been attributed to yacon leaves, which are dried and used in the preparation of tea [12]. Previous biological works have demonstrated antiinflammatory, antifungal, and antibacterial activities $[13,14]$. Different chemical compounds such as phenolic and entkaurenoic acids, related diterpenoid substances, acetophenone phytoalexins, and sesquiterpene lactones (STLs) were identified in yacon leaves $[15,16]$.

We have already shown that STLs, mainly occurring in the Asteraceae family, represent a class of compounds with potential as trypanocidal leads [17-19]. Given the increasing interest that yacon has raised in recent years due to its health promoting properties, its potential as a medicinal plant, and its content in STLs, we have selected S. sonchifolius in the search for trypanocidal molecules against T. cruzi.

\section{Materials and Methods}

2.1. Plant Material. Leaves of Smallanthus sonchifolius (Poepp. \& Endl.) H. Robinson (Asteraceae), clone LIEY 97-2, were collected in May 2010 from experimental crops located at Centro Universitario "Horco Molle," Universidad Nacional de Tucumán $\left(26^{\circ} 47^{\prime} \mathrm{S}, 65^{\circ} 19^{\prime} \mathrm{W}, 547 \mathrm{~m}\right.$ a.s.l.). A voucher specimen was deposited at the Herbarium of Instituto Miguel Lillo, S. M. de Tucumán, Argentina (LIL 607176).

2.2. Extraction of Plant Material. Approximately $350 \mathrm{~g}$ of air-dried and ground leaves were extracted by soaking in dichloromethane $(6.8 \mathrm{~L})$ at room temperature for $30 \mathrm{~min}$. The procedure was repeated, and the filtrates combined. Evaporation of the solvent under reduced pressure provided $9.29 \mathrm{~g}$ of organic extract (OE; 2.65\%).

2.3. Bioassay-Guided Fractionation of $O E$ and Isolation of Compounds. The $\mathrm{OE}(9.0 \mathrm{~g})$ was separated by column chromatography (CC) on silica gel 60 (Merck, 0.063$0.2 \mathrm{~mm} / 70-230 \mathrm{mesh} ; 67 \mathrm{~g})$ affording 10 fractions $\left(F_{1 \mathrm{~A}}-F_{5 \mathrm{~B}}\right)$. Each fraction was eluted with $250 \mathrm{~mL}$ of the following eluents: n-hexane $100 \%\left(F_{1 \mathrm{~A}}-F_{1 \mathrm{~B}}\right), n$-hexane : ethyl acetate $1: 1\left(F_{2 \mathrm{~A}}-\right.$ $\left.F_{2 \mathrm{~B}}\right)$, ethyl acetate $100 \%\left(F_{3 \mathrm{~A}}-F_{3 \mathrm{~B}}\right)$, ethyl acetate : methanol 1:1 $\left(F_{4 \mathrm{~A}}-F_{4 \mathrm{~B}}\right)$, and methanol $100 \%\left(F_{5 \mathrm{~A}}-F_{5 \mathrm{~B}}\right)$. Eluates were monitored by thin-layer chromatography (TLC) using silica gel $60 F_{254}$ (Merck) using hexane : ethyl acetate 1:1 as mobile phase. Visualization of compounds was done by a solution of anisaldehyde/sulfuric acid followed by heating.

Fractions $F_{2 \mathrm{~B}}$ and $F_{3 \mathrm{~A}}$ were separately chromatographed over silica gel CC (10 g) and eluted isocratically with $n$ hexane:ethyl acetate $(1: 1)$ as mobile phase yielding 20 subfractions of $F_{2 \mathrm{~B}}\left(F_{2 \mathrm{~B} 1}-F_{2 \mathrm{~B} 20}\right)$ and 22 subfractions from $F_{3 \mathrm{~A}}$ $\left(F_{3 \mathrm{~A} 1}-F_{3 \mathrm{~A} 22}\right)$, of $10 \mathrm{~mL}$ each. According to their TLC profile, fractions $F_{2 \mathrm{~B} 5}-F_{2 \mathrm{~B} 7} ; F_{2 \mathrm{~B} 8}-F_{2 \mathrm{~B} 12} ; F_{3 \mathrm{~A} 6}-F_{3 \mathrm{~A} 8}$ and $F_{3 \mathrm{~A} 9}-F_{3 \mathrm{~A} 13}$ were pooled and subjected to preparative TLC on silica gel 60 employing $n$-hexane : ethyl acetate $1: 1$ as mobile phase to afford compounds $\mathbf{1}, \mathbf{2}$, and 3.

These compounds were recrystallized from ethanol at $96^{\circ} \mathrm{C}$ and identified by spectroscopic techniques: ${ }^{1} \mathrm{H}$ - and ${ }^{13} \mathrm{C}$-nuclear magnetic resonance (NMR), gas chromatography coupled to mass spectrometry (GC/MS), and infrared spectroscopy (IR).

2.4. Identification of Compounds 1, 2, and 3. The structure elucidation of the isolated compounds was performed by proton nuclear magnetic resonance $\left({ }^{1} \mathrm{H}\right.$ NMR) and carbon NMR $\left({ }^{13} \mathrm{C}\right.$ NMR) (Bruker $300 \mathrm{MHz}-\mathrm{Karlsruhe,} \mathrm{Germany).} \mathrm{Com-}$ pounds were dissolved in deuterated chloroform $\left(\mathrm{Cl}_{3} \mathrm{CD}\right)$, and tetramethylsilane (TMS) was used as internal standard (Sigma). FTIR spectra were recorded on a Nicolet 380 spectrometer using $\mathrm{KBr}$ pellets. The material was dried and placed in a desiccator at $20^{\circ} \mathrm{C}$ prior to pellet preparation. Gas chromatography/mass spectroscopy spectra were recorded on a Agilent 5973 network mass selective detector (MS), Agilent 6890 Series GC system (GC).

2.5. Parasites, Cell Lines, and Media. T. cruzi epimastigotes (RA strain) were grown in liver infusion tryptose medium (LIT) supplemented with 10\% fetal bovine serum (Natocor). Cultures were routinely maintained by weekly passages at $28^{\circ} \mathrm{C}$. T. cruzi trypomastigotes were routinely maintained by infecting 21-day-old male CF1 mice. T. cruzi amastigotes were obtained by infecting J774 cells with bloodstream trypomastigotes.

2.6. In Vitro Trypanocidal Activity against T. cruzi Epimastigotes and Trypomastigotes. S. sonchifolius $\mathrm{OE}$ and fractions $F_{1 \mathrm{~A}}-F_{5 \mathrm{~B}}$ were tested for trypanocidal activity against $T$. cruzi epimastigotes, at final concentrations of $10 \mu \mathrm{g} / \mathrm{mL}$ and $100 \mu \mathrm{g} / \mathrm{mL}$, by a $\left[{ }^{3} \mathrm{H}\right.$ ] thymidine uptake assay as previously described [17]. Compounds 1, 2, and 3 were tested at final concentrations ranging from $0.01 \mu \mathrm{g} / \mathrm{mL}$ to $50 \mu \mathrm{g} / \mathrm{mL}$. Stock solutions of the samples were prepared in ethanol: water $(1: 1)$. Epimastigotes in exponential growth phase were adjusted to $1.5 \times 10^{6}$ parasites/mL and seeded on 96 -well plates in the presence of the different concentrations of $\mathrm{OE}$, fractions, or compounds. Parasites were cultured in triplicate for $72 \mathrm{~h}$. Control parasites were cultured in absence or presence of benznidazole $(20 \mu \mathrm{M}$; Roche-Rio de Janeiro, 
Brazil). Percentage inhibition was calculated as $100-\{[(\mathrm{cpm}$ of treated parasites)/(cpm of untreated parasites) $] \times 100\}$. The compound concentration at which the parasite growth was inhibited by $50 \%$ (inhibitory concentration $50, \mathrm{IC}_{50}$ ) was determined after $72 \mathrm{~h}$.

To determine whether the parasites could recover after treatment with the pure compounds, $T$. cruzi epimastigotes were incubated with compounds $\mathbf{1}-\mathbf{3}(0.1,1$, and $10 \mu \mathrm{g} / \mathrm{mL})$ for $24 \mathrm{~h}$. Parasites were then centrifuged at $3000 \mathrm{rpm}$ for $10 \mathrm{~min}$, resuspended in fresh medium, and incubated for 2 additional days, counting the number of parasite in a Neubauer chamber on a daily basis.

The trypanocidal effect of compounds $\mathbf{1}, \mathbf{2}$, and $\mathbf{3}$ was also tested on bloodstream trypomastigotes as previously described [17]. Briefly, mouse blood containing trypomastigotes was adjusted to a concentration of $1.5 \times 10^{6}$ parasite $/ \mathrm{mL}$ and seeded ( $150 \mu \mathrm{L} /$ well) by duplicate into a 96 -well microplate, in the presence of each compound ( 1 to $50 \mu \mathrm{g} / \mathrm{mL}$, final concentration). Plates were incubated for $24 \mathrm{~h}$, and the remaining live parasites were counted in a haemocytometer.

2.7. In Vitro Trypanocidal Activity against T. cruzi Amastigotes. To evaluate the effect of compounds 1-3 on intracellular forms of T. cruzi, 96-well plates were seeded with J774 murine macrophages at $5 \times 10^{3}$ per well in $100 \mu \mathrm{L}$ of culture medium and incubated for $2 \mathrm{~h}$ at $37^{\circ} \mathrm{C}$ in a $5 \%$ $\mathrm{CO}_{2}$ atmosphere. Cells were infected with transfected blood trypomastigotes expressing $\beta$-galactosidase at a parasite : cell ratio of $10: 1$. After $2 \mathrm{~h}$ of coculture, plates were washed twice with PBS to remove free parasites and compounds $\mathbf{1 - 3}$ were added at $0.1-50 \mu \mathrm{g} / \mathrm{mL}$ per well in $150 \mu \mathrm{L}$ of fresh complete RPMI medium without phenol red (Gibco, Rockville, MD). Controls included infected nontreated cells (100\% infection control) and uninfected cells ( $0 \%$ infection control). The assay was developed $48 \mathrm{~h}$ later by addition of chlorophenol red- $\beta$-d-galactopyranoside ( $100 \mu \mathrm{M}$ CPRG) and $1 \%$ Nonidet $\mathrm{P} 40$. Plates were incubated for $4-6 \mathrm{~h}$ at $37^{\circ} \mathrm{C}$. Wells with galactosidase activity turned the media from yellow to red, and this reaction was quantified at $590 \mathrm{~nm}$ in a microplate reader (Bio-Rad Laboratories, Hercules, CA). Percentage inhibition was calculated as $100-\{[$ (absorbance of treated infected cells)/(absorbance of untreated infected cells) $] \times 100\}$ and the $\mathrm{IC}_{50}$ value calculated.

2.8. Cytotoxicity Assay. The cytotoxic effect of compounds 1,2 , and 3 on Vero cells was evaluated by using the MTT tetrazolium salt (3-(4,5-dimethylthiazol-2-yl)-2,5diphenyltetrazolium bromide) (Sigma) colorimetric assay. Cells $\left(5 \times 10^{4}\right.$ cells/well $)$ were seeded at a final volume of $150 \mu \mathrm{L}$ in a flat-bottom 96-well microplate and cultured at $37^{\circ} \mathrm{C}$ in a $5 \% \mathrm{CO}_{2}$ atmosphere in the absence or presence of increasing concentrations of the compounds $(1-50 \mu \mathrm{g} / \mathrm{mL})$. After $24 \mathrm{~h}$, MTT was added at a final concentration of $1.5 \mathrm{mg} / \mathrm{mL}$ and plates were incubated for $2 \mathrm{~h}$ at $37^{\circ} \mathrm{C}$. The purple formazan crystals were completely dissolved by adding $150 \mu \mathrm{L}$ of ethanol, and the absorbance was detected at $570 \mathrm{~nm}$ in a microplate reader. Results were calculated as the ratio between optical density in the presence and absence of the compound multiplied by 100 . The $50 \%$ cytotoxic

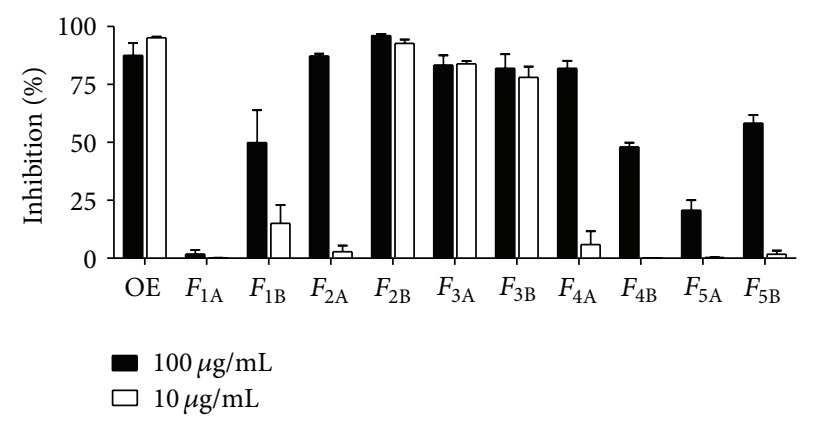

FIGURE 1: Growth inhibition of T. cruzi epimastigotes by S. sonchifolius $\mathrm{OE}$ and fractions $F_{1 \mathrm{~A}}$ to $F_{5 \mathrm{~B}}$. Epimastigotes were cultured in triplicate in the presence of 10 or $100 \mu \mathrm{g} / \mathrm{mL}$ of OE or each fraction. Cultures were done in 96 -well plates with $1.5 \times 10^{6}$ parasites $/ \mathrm{mL}$ during $72 \mathrm{~h}$ with the addition of $\left[{ }^{3} \mathrm{H}\right]$ thymidine for the last $16 \mathrm{~h}$. Bars represent means \pm SEM.

concentration $\left(\mathrm{CC}_{50}\right)$ was calculated for each compound. All experiments were made in duplicate.

The selectivity index (SI) of each compound was calculated as the $\mathrm{CC}_{50}$ obtained with Vero cells divided by the $\mathrm{IC}_{50}$ obtained against T. cruzi amastigotes.

2.9. Statistical Analysis. All values were presented as mean \pm SEM The GraphPad Prism 3.0 software (GraphPad Software Inc., San Diego, CA) was employed to carry out calculations. To calculate the $\mathrm{IC}_{50}$ values, the percentages of inhibition were plotted against the drug concentration and fitted with a straight line determined by a linear regression (Sigma Plot 10 software). Results presented are representative of three to four independent experiments.

\section{Results}

3.1. In Vitro Trypanocidal Activity of S. sonchifolius OE. The trypanocidal activity of the organic extract of $S$. sonchifolius $(\mathrm{OE})$ was evaluated in vitro against $T$. cruzi epimastigotes by a $\left[{ }^{3} \mathrm{H}\right]$ thymidine uptake assay. The extract was found to be active showing a growth inhibition of $87.6 \% \pm 5.3$ and $95.1 \% \pm$ 0.5 at 100 and $10 \mu \mathrm{g} / \mathrm{mL}$, respectively.

The fractionation of the OE by CC yielded 10 fractions $\left(F_{1 \mathrm{~A}}-F_{5 \mathrm{~B}}\right)$, the effects of which were tested against epimastigote forms of T. cruzi as described previously (Figure 1). The results showed that at the lowest concentration tested $(10 \mu \mathrm{g} / \mathrm{mL})$ fractions $F_{2 \mathrm{~B}}, F_{3 \mathrm{~A}}$, and $F_{3 \mathrm{~B}}$ showed the highest trypanocidal activity with percentages of growth inhibition of $92.7 \pm 1.7 \%, 83.8 \pm 1.1 \%$, and $82.7 \pm 1.0 \%$, respectively.

3.2. Bioassay-Guided Fractionation of S. sonchifolius OE. The bioassay-guided fractionation of fractions $F_{2 \mathrm{~B}}$ and $F_{3 \mathrm{~A}}$ led to the isolation of compounds $\mathbf{1}, \mathbf{2}$, and $\mathbf{3}$ that were purified by a combination of column chromatography, preparative TLC, and precipitation techniques. Compound 1 (35 mg; $0.39 \%)$, compound 2 (6.4 mg;0.07\%), and compound 3 ( $2.4 \mathrm{mg} ; 0.03 \%)$ were identified by comparing their spectral data with published values [20-22] as the STLs enhydrin 


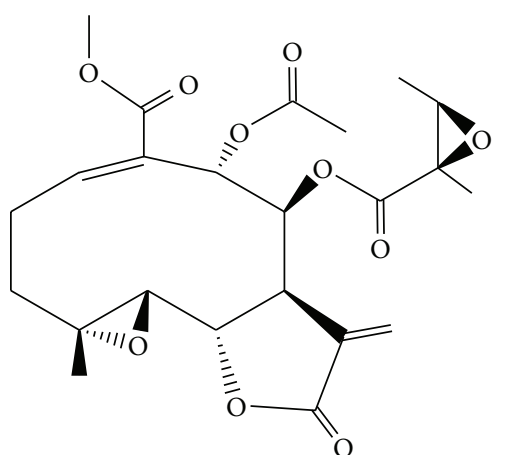

Enhydrin

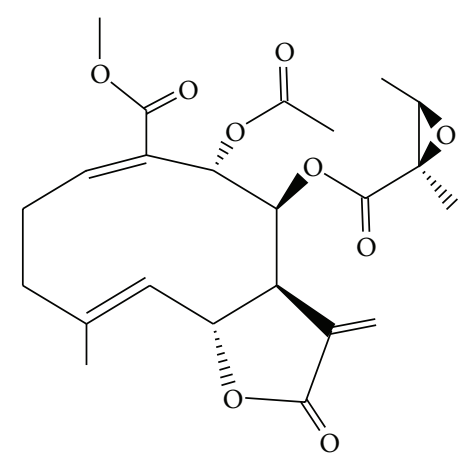

Uvedalin

(a)

(b)

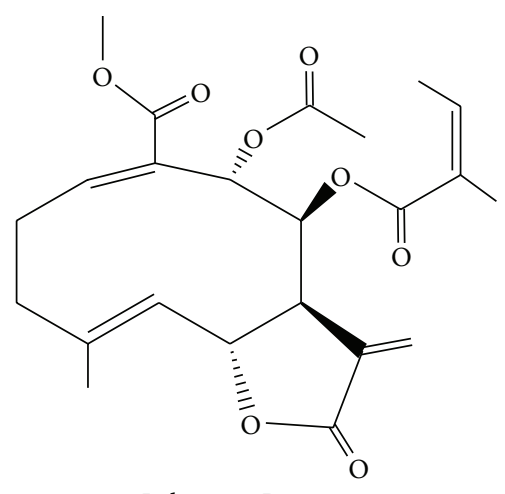

Polymatin B

FIgURE 2: Chemical structures of the sesquiterpene lactones enhydrin, uvedalin, and polymatin B.

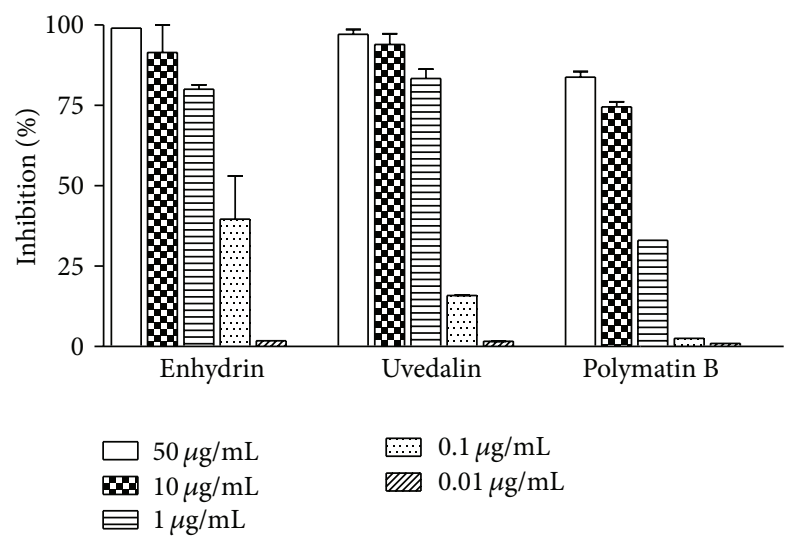

FIgURE 3: Inhibition of T. cruzi epimastigotes growth by enhydrin, uvedalin, and polymatin B. Parasites were adjusted at $1.5 \times 10^{6} / \mathrm{mL}$ and incubated in triplicate in the presence of 0.01 to $50 \mu \mathrm{g} / \mathrm{mL}$ of each compound. Parasites were cultured for $72 \mathrm{~h}$, with the addition of $\left[{ }^{3} \mathrm{H}\right]$ thymidine for the last $16 \mathrm{~h}$.

( $4 \alpha, 5 \beta$-epoxy- $8 \beta$-( $\left.2^{\prime} S, 3^{\prime} S\right)$-epoxyangeloyloxy- $9 \alpha$-acetyloxy1(10)E,11(13)-germacradien-12,6 $\alpha$-olide-14-oic-acid methyl ester), uvedalin ( $8 \beta-\left(2^{\prime} S, 3^{\prime} S\right)$-epoxyangeloyloxy- $9 \alpha$-acetyloxy-1(10)E,4E,11(13)-germacratrien-12,6 $\alpha$-olide-14-oic acid methyl ester), and polymatin $B$ ( $8 \beta$-angeloyloxi- $9 \alpha$-acetyloxi1(10)E,4E,11(13)-germacratrien-12,6 $\alpha$-olide-14-oic acid methyl ester) (Figure 2). Purity of the compounds (>95\%) was confirmed by gas chromatography (GC).

3.3. In Vitro Trypanocidal Activity against T. cruzi Epimastigotes and Trypomastigotes. The $\mathrm{IC}_{50}$ values of the pure compounds were calculated on different T. cruzi evolutive stages. Figure 3 shows the effect of the pure compounds on the growth of epimastigotes of $T$. cruzi. The $\mathrm{IC}_{50}$ values for enhydrin, uvedalin, and polymatin B were $0.39 \mu \mathrm{g} / \mathrm{mL}(0.84 \mu \mathrm{M})$, $0.49 \mu \mathrm{g} / \mathrm{mL}(1.09 \mu \mathrm{M})$, and $2.12 \mu \mathrm{g} / \mathrm{mL}(4.90 \mu \mathrm{M})$, respectively, after $72 \mathrm{~h}$ of incubation.

Moreover, after the $24 \mathrm{~h}$ treatment with $10 \mu \mathrm{g} / \mathrm{mL}$ enhydrin or uvedalin, a drastic reduction in the amount of parasites could be observed. Besides, two days after removal of the compounds, no recuperation of the epimastigotes was observed suggesting that $24 \mathrm{~h}$ treatment at high doses is sufficient to kill the parasites (Figure 4 ). When $0.1 \mu \mathrm{g} / \mathrm{mL}$ of polymatin B was removed at $24 \mathrm{~h}$ after treatment, epimastigotes recovered their replication rates at values similar to the control parasites.

The effect of the compounds against the infective form of T. cruzi is shown in Figure 5. When bloodstream trypomastigotes were incubated with the pure STLs, we observed that enhydrin and uvedalin were active with $\mathrm{IC}_{50}$ values of $15.5 \mu \mathrm{g} / \mathrm{mL}(33.4 \mu \mathrm{M})$ and $11.2 \mu \mathrm{g} / \mathrm{mL}(25.0 \mu \mathrm{M})$, respectively. By contrast, polymatin B showed no activity against this parasite form.

3.4. In Vitro Trypanocidal Activity against T. cruzi Amastigotes. In order to evaluate the ability of the pure compounds to inhibit the intracellular amastigote forms of T. cruzi, J774 macrophages were infected with transfected blood trypomastigotes expressing $\beta$-galactosidase. Forty-eight hours after the addition of the pure compounds, the percentage of inhibition was determined. All the tested STLs were able to inhibit amastigotes replication with $\mathrm{IC}_{50}$ values of $2.4,1.5$, and $3.9 \mu \mathrm{g} / \mathrm{mL}(5.17,3.34$, and $9.02 \mu \mathrm{M})$ for enhydrin, uvedalin, and polymatin B, respectively (Figure 6).

3.5. Cytotoxicity Activity in Vero Cells. In vitro cytotoxicity of the STLs on Vero cells was analyzed using the MTT assay. Results are shown in Figure 7. When cell suspensions were treated with enhydrin, uvedalin, and polymatin $\mathrm{B}$, the $\mathrm{CC}_{50}$ were $21.6,21.0$, and $63.7 \mu \mathrm{g} / \mathrm{mL}(46.5,46.8$, and $147.3 \mu \mathrm{M})$, respectively. The SI was used to compare the toxicity for mammalian cells and the activity against the parasites. The SI for the intracellular form of the parasites was 9,14 , and 16.3 for enhydrin, uvedalin, and polymatin B, respectively.

\section{Discussion}

In this work, the trypanocidal activity of the species Smallanthus sonchifolius has been evaluated by in vitro assays. The dichloromethane extract (OE) of this plant induced a 


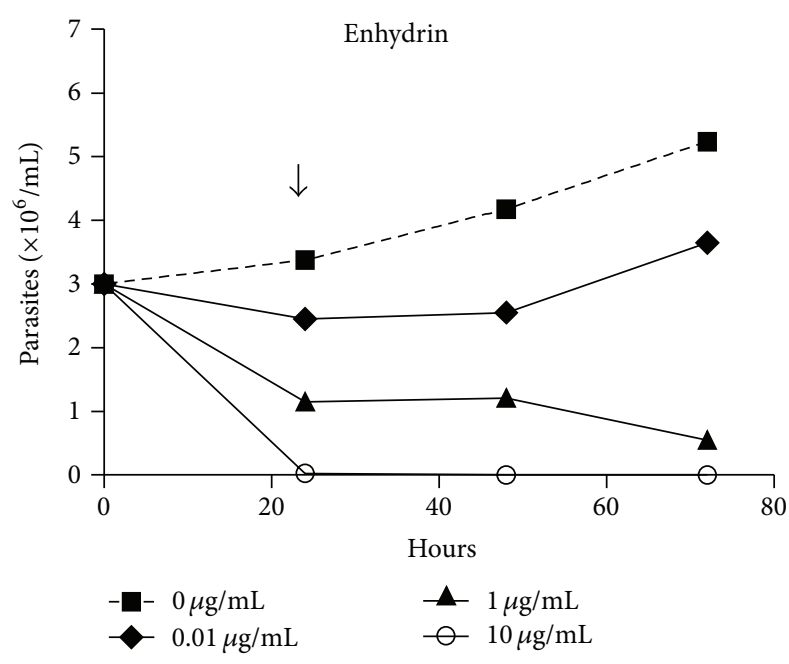

(a)

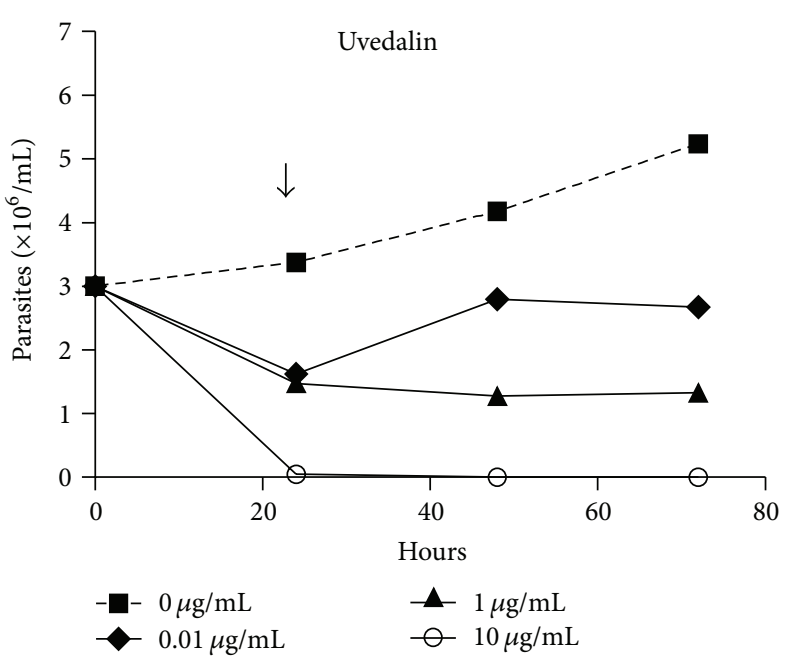

(b)

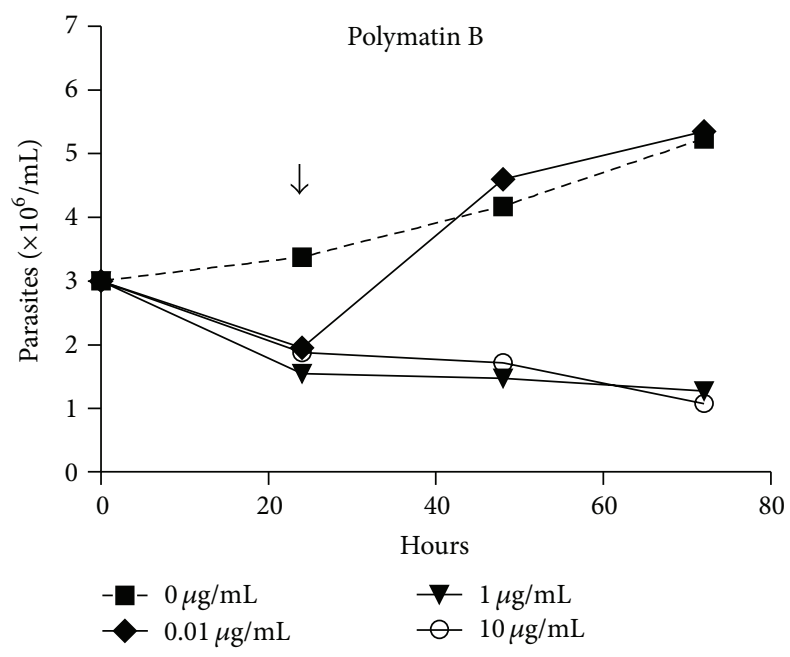

(c)

FIGURE 4: Residual effect of enhydrin, uvedalin, and polymatin B on the growth of T. cruzi epimastigotes. Parasites were incubated in the absence or presence of $0-10 \mu \mathrm{g} / \mathrm{mL}$ of the compounds for $24 \mathrm{~h}$. The culture medium was replaced by a fresh one (arrow) without the compound, and parasites were allowed to grow for 2 days. Parasites were counted in a Neubauer chamber. Symbols represent the mean \pm SEM.

significant growth inhibition (95.1\%) when tested against $T$. cruzi epimastigotes at a concentration of $10 \mu \mathrm{g} / \mathrm{mL}$. This result prompted us to carry out a bioassay-guided fractionation of the OE by chromatographic techniques. Among the tested fractions, $F_{2 \mathrm{~B}}, F_{3 \mathrm{~A}}$, and $F_{3 \mathrm{~B}}$ presented the highest in vitro inhibitory activity, against epimastigotes, with percentages of growth inhibition higher than $80 \%$ at the lower concentration tested. Further purification of $F_{2 \mathrm{~B}}$ and $F_{3 \mathrm{~A}}$, by a series of chromatographic separations, led to the isolation of three structurally related germacranolide STLs of the melampolide type, which were identified as enhydrin, uvedalin, and polymatin B.

STLs are naturally occurring plant terpenoids with over 5000 known structures and which are mainly present in members of the Asteraceae family [23]. They exhibit a variety of skeletal arrangements and are the largest and most diverse category of natural products with an $\alpha$-methylene- $\gamma$-lactone motif [3]. STLs have been related to a broad spectrum of biological activities ranging from anticancer, antiviral, antibacterial, antifungal, and antiprotozoal. Many are described as the active constituents of medicinal plants used in traditional medicine for the treatment of inflammatory diseases [24]. The vast majority of STLs are considered quite "drug-like" molecules with respect to their physicochemical properties [25].

Enhydrin, uvedalin, and polymatin B were firstly evaluated for their trypanocidal activity on T. cruzi epimastigotes showing a marked activity with $\mathrm{IC}_{50}$ values of $0.84 \mu \mathrm{M}$, $1.09 \mu \mathrm{M}$, and $4.90 \mu \mathrm{M}$, respectively. These values indicated that an increase in the trypanocidal activity was achieved along the purification process.

Besides, epimastigotes treated for $24 \mathrm{~h}$ with $10 \mu \mathrm{g} / \mathrm{mL}$ of enhydrin or uvedalin were not able to recover their initial replication rates suggesting that the treatment at high doses was sufficient to kill the parasites. Parasites treated with either 


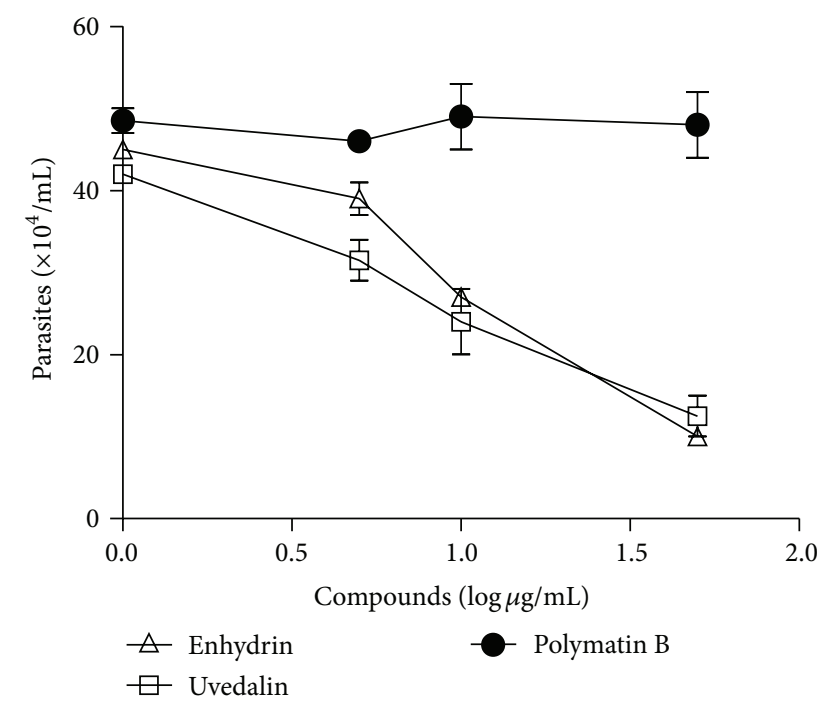

FIGURE 5: Effect of enhydrin, uvedalin, and polymatin B on $T$. cruzi trypomastigotes. Bloodstream trypomastigotes were cultured in duplicate in the presence of 1 to $50 \mu \mathrm{g} / \mathrm{mL}$ of the compounds. The assay was performed employing $1.5 \times 10^{6}$ parasites $/ \mathrm{mL}$ over $24 \mathrm{~h}$. Remaining live parasites were counted in a Neubauer chamber. Symbols represent the mean \pm SEM.

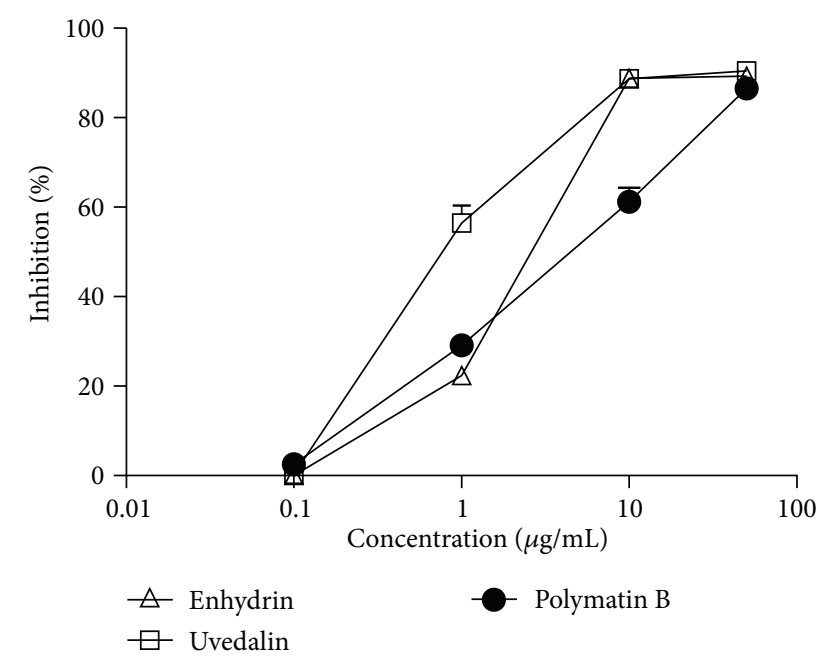

FIGURE 6: Effect of enhydrin, uvedalin, and polymatin B on T. cruzi amastigotes. J774 phagocytic cells were infected with transfected trypomastigotes expressing $\beta$-galactosidase (10:1 parasite : cell ratio). After removing free parasites, STLs were added at concentrations ranging from 0.1 to $50 \mu \mathrm{g} / \mathrm{mL}$. Three days after infection, nonidet $\mathrm{P} 40$ and chlorophenol red- $\beta$-d-galactopyranoside (CPRG) were added and the galactosidase activity was determined at $590 \mathrm{~nm}$. Values represent the mean \pm SEM.

enhydrin or uvedalin, at $1 \mu \mathrm{g} / \mathrm{mL}$, or with polymatin $\mathrm{B}$, at $10 \mu \mathrm{g} / \mathrm{mL}$, presented a reduction in the replication rate that was close to $50 \%$ at $24 \mathrm{~h}$ after treatment. On the other hand, recovery was evident when $0.1 \mu \mathrm{g} / \mathrm{mL}$ of the compounds was employed.

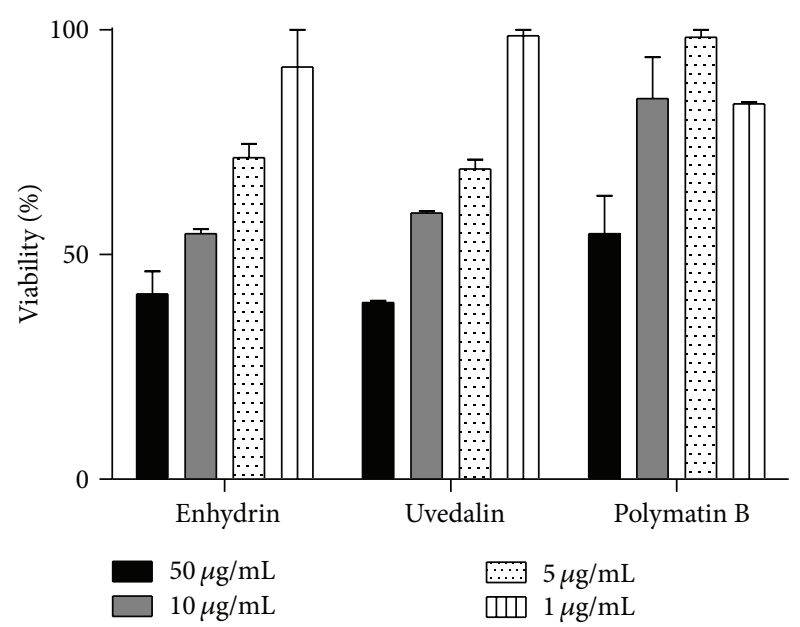

FIgURE 7: Cytotoxicity of enhydrin, uvedalin, and polymatin B on Vero cells. Cultures were kept for $24 \mathrm{~h}$ in the presence of different concentrations ( 1 to $50 \mu \mathrm{g} / \mathrm{mL}$ ) of the STLs. Cell viability was determined by the MTT method and was expressed as the ratio between viable cells in the presence and absence of the compound multiplied by 100 . Bars represent the mean \pm SEM of three experiments carried out in duplicate.

When the isolated compounds were evaluated against T. cruzi trypomastigotes, the results $\left(\mathrm{IC}_{50}=33.4 \mu \mathrm{M}\right.$ for enhydrin and $\mathrm{IC}_{50}=25.0 \mu \mathrm{M}$ for uvedalin) showed that this parasite stage is less sensitive than epimastigotes to the compounds. During the initial acute phase of infection, the nonreplicative bloodstream trypomastigotes invade different mammalian cell types, where they transform into replicative intracellular amastigotes and multiply within the host's cells cytoplasm. Interestingly, when enhydrin, uvedalin, and polymatin B were tested against the amastigote forms, they were able to inhibit replication. The three STLs were active with $\mathrm{IC}_{50}$ values of $5.17 \mu \mathrm{M}, 3.34 \mu \mathrm{M}$, and $9.02 \mu \mathrm{M}$, respectively. The ability of compounds to inhibit the intracellular growth of T. cruzi amastigotes is a more rigorous and relevant test of anti-T. cruzi activity, as it is applied to a stage which is the predominant form in mammals and because the killing assay requires that the drug cross the host cell membrane [26]. It is well known that the treatment with benznidazole is especially useful for patients in the acute phase, when trypomastigotes may be easily found in blood, while its effectiveness during the asymptomatic or chronic stage, is still controversial. The fact that these compounds proved to be active against amastigotes is of particular interest, since the DNDi organization prioritizes the development of drugs that are useful during the indeterminate and chronic phases of the infection, where parasites remain intracellular [1].

The therapeutic potential and the lack of cytotoxic effects on mammalian cells are important criteria to be considered when novel compounds with activity against $T$. cruzi are investigated. Compounds containing an exomethylene moiety conjugated with a carbonyl group can react as Michaeltype acceptors with the thiol groups of macromolecules such as enzymes [3]. The presence of this reactive group in the isolated STLs could explain the trypanocidal effects and 
the cytotoxicity of these compounds. When analyzing the chemical structure of the STLs isolated in this work, it could be observed that, unlike enhydrin and uvedalin, polymatin B does not present an epoxide as substituent. Biological activity of $\alpha$-methylene- $\gamma$-lactones may vary according to their different number of alkylating structure elements such as conjugated cyclopentones, conjugated side-chain esters, and epoxides [25]. These features may be related to the increased activity shown by enhydrin and uvedalin compared to the nonepoxide substituted polymatin B. Moreover, when comparing the toxicity of the lactones in Vero cells with the activity against $T$. cruzi amastigotes, we could observe that enhydrin, uvedalin, and polymatin B had some selective toxicity against the parasites (SI of 9, 14, and 16.3, resp.).

The three STLs had been previously isolated from $S$. sonchifolius [11, 13, 15]. Enhydrin and uvedalin have shown cytotoxic activity in cervical cancer cells [27]. For enhydrin hypoglycemic, antibacterial, anti-inflammatory, and antihyperalgesic activities have also been reported $[11,28,29]$, while this is the first report of the anti T. cruzi activity of these compounds.

\section{Conclusion}

Three STLs with promising antitrypanocidal properties were isolated from the leaves of S. sonchifolius by a bioassayguided fractionation method. The compounds, identified as enhydrin, uvedalin, and polymatin B, efficiently inhibited both the epimastigote and the replicative intracellular amastigotes, being more selective for the parasites than for mammalian cells. According to the results obtained, enhydrin and uvedalin may be considered promising antitrypanosomal lead molecules. However, the potential of these compounds still have to be improved by obtaining derivatives that might be used as therapeutic agents against the parasite.

Further studies will involve evaluation of the underlying mechanisms as well as in vivo studies of enhydrin and uvedalin.

\section{Conflict of Interests}

The authors declare that they have no conflict of interests.

\section{Authors' Contribution}

F. M. Frank, J. Ulloa, S. I. Cazorla, C. Catalán, and L. V. Muschietti contributed equally to this paper.

\section{Acknowledgments}

This research was supported in part by grants from ANPCyT (PICT-2006-608 and PICT-2010-657), CONICET (PIP 01540), and UBACYT (20020110200114, 20020090200478, and 20020100100201).

\section{References}

[1] "Drugs for Neglected Diseases Initiative (DNDi)," http://www .dndi.org/.
[2] J. A. Urbina, "Specific chemotherapy of Chagas disease: relevance, current limitations and new approaches," Acta Tropica, vol. 115, no. 1-2, pp. 55-68, 2010.

[3] A. Janecka, A. Wyrebska, K. Gach, J. Fichna, and T. Janecki, "Natural and synthetic $\alpha$-methylenelactones and $\alpha$-methylenelactams with anticancer potential," Drug Discovery Today, vol. 17, no. 11-12, pp. 561-572, 2012.

[4] J.-R. Ioset, "Natural products for neglected diseases: a review," Current Organic Chemistry, vol. 12, no. 8, pp. 643-666, 2008.

[5] E. Izumi, T. Ueda-Nakamura, V. F. Veiga Júnior, and C. V. Nakamura, "Natural products and Chagas' disease: a review of plant compounds studied for activity against Trypanosoma cruzi," Natural Product Reports, vol. 28, no. 4, pp. 809-823, 2011.

[6] T. J. Schmidt, S. A. Khalid, A. J. Romanha et al., "The potential of secondary metabolites from plants as drugs or leads against protozoan neglected diseases-part I," Current Medicinal Chemistry, vol. 19, no. 4, pp. 2128-2175, 2012.

[7] T. J. Schmidt, S. A. Khalid, A. J. Romanha et al., "The potential of secondary metabolites from plants as drugs or leads against protozoan neglected diseases-part II," Current Medicinal Chemistry, vol. 19, no. 4, pp. 2176-2228, 2012.

[8] A. G. Tempone, P. Sartorelli, C. Mady, and F. Fernandes, "Natural products to anti-trypanosomal drugs: an overview of new drug prototypes for American trypanosomiasis," Cardiovascular and Hematological Agents in Medicinal Chemistry, vol. 5, no. 3, pp. 222-235, 2007.

[9] C. W. Wright, "Recent developments in research on terrestrial plants used for the treatment of malaria," Natural Product Reports, vol. 27, no. 7, pp. 961-968, 2010.

[10] I. Ojansivu, C. L. Ferreira, and S. Salminen, "Yacon, a new source of prebiotic oligosaccharides with a history of safe use," Trends in Food Science \& Technology, vol. 22, no. 1, pp. 40-46, 2011.

[11] A. Grau and J. Rea, Andean Roots and Tubers, International Plant Genetic Resources Institute (IPGRI), Rome, Italy, 1997.

[12] S. B. Genta, W. M. Cabrera, M. I. Mercado, A. Grau, C. A. Catalán, and S. S. Sánchez, "Hypoglycemic activity of leaf organic extracts from Smallanthus sonchifolius: constituents of the most active fractions," Chemico-Biological Interactions, vol. 185, no. 2, pp. 143-152, 2010.

[13] A. Inoue, S. Tamogami, H. Kato et al., "Antifungal melampolides from leaf extracts of Smallanthus sonchifolius," Phytochemistry, vol. 39, no. 4, pp. 845-848, 1995.

[14] F. Lin, M. Hasegawa, and O. Kodama, "Purification and identification of antimicrobial sesquiterpene lactones from yacon (Smallanthus sonchifolius) leaves," Bioscience, Biotechnology and Biochemistry, vol. 67, no. 10, pp. 2154-2159, 2003.

[15] M. I. Mercado, M. V. Coll Aráoz, A. Grau, and C. A. N. Catalán, "New acyclic diterpenic acids from yacon (Smallanthus sonchifolius) leaves," Natural Product Communications, vol. 5, no. 11, pp. 1721-1726, 2010.

[16] S. S. Hong, S. A. Lee, X. H. Han et al., "Melampolides from the leaves of Smallanthus sonchifolius and their inhibitory activity of LPS-induced nitric oxide production," Chemical \& Pharmaceutical Bulletin, vol. 56, no. 2, pp. 199-202, 2008.

[17] V. P. Sülsen, F. M. Frank, S. I. Cazorla et al., "Trypanocidal and leishmanicidal activities of sesquiterpene lactones from Ambrosia tenuifolia Sprengel (Asteraceae)," Antimicrobial Agents and Chemotherapy, vol. 52, no. 7, pp. 2415-2419, 2008.

[18] V. Sülsen, P. Barrera, L. Muschietti, V. Martino, and M. Sosa, "Antiproliferative effect and ultrastructural alterations induced 
by psilostachyin on Trypanosoma cruzi," Molecules, vol. 15, no. 1, pp. 545-553, 2010.

[19] V. P. Sülsen, F. M. Frank, S. I. Cazorla et al., "Psilostachyin C: a natural compound with trypanocidal activity," International Journal of Antimicrobial Agents, vol. 37, no. 6, pp. 536-543, 2011.

[20] B. S. Joshi, V. N. Kamat, and H. Fuhrer, "Revised structure of enhydrin,” Tetrahedron Letters, vol. 12, no. 26, pp. 2373-2376, 1971.

[21] W. Herz and S. V. Bhat, "Isolation and structure of two new germacranolides from Polymnia uvedalia (L.) L," Journal of Organic Chemistry, vol. 35, no. 8, pp. 2605-2611, 1970.

[22] N. Le Van and N. H. Fischer, "Three new melampolide sesquiterpenes, polymatin A, B and C, from Polymnia maculata Cav. var. maculata," Phytochemistry, vol. 18, no. 5, pp. 851-854, 1979.

[23] J. Buckingham, A. M. Hodgson, and S. P. Walford, Eds., The Dictionary of Natural Products on CDROM, Chapman \& Hall/ CRC, Boca Raton, Fla, USA, 2002.

[24] D. Chaturvedi, "Sesquiterpene lactones: structural diversity and their biological activities," in Opportunity, Challenge and Scope of Natural Products in Medicinal Chemistry, pp. 313-334, Research Signpost, Kerala, India, 2011.

[25] T. J. Schmidt, "Structure-activity relationships of sesquiterpene lactones," in Studies in Natural Products Chemistry, Atta-urRahman, Ed., vol. 33, pp. 309-392, Elsevier Science, Amsterdam, The Netherlands, 2006.

[26] A. M. C. Canavaci, J. M. Bustamante, A. M. Padilla et al., "In vitro and in vivo high-throughput assays for the testing of antiTrypanosoma cruzi compounds," PLoS Neglected Tropical Diseases, vol. 4, no. 7, article e740, 2010.

[27] D. Siriwan, T. Naruse, and H. Tamura, "Effect of epoxides and $\alpha$-methylene- $\gamma$-lactone skeleton of sesquiterpenes from yacon (Smallanthus sonchifolius) leaves on caspase-dependent apoptosis and NF- $\kappa$ B inhibition in human cercival cancer cells," Fitoterapia, vol. 82, no. 7, pp. 1093-1101, 2011.

[28] J. G. Choi, O. H. Kang, Y. S. Lee et al., "Antimicrobial activity of the constituents of Smallanthus sonchifolius leaves against methicillin-resistant Staphylococcus aureus," European Review for Medical and Pharmacological Sciences, vol. 14, no. 12, pp. 10051009, 2010.

[29] M. W. Feltenstein, W. Schühly, J. E. Warnick, N. H. Fischer, and K. J. Sufka, "Anti-inflammatory and anti-hyperalgesic effects of sesquiterpene lactones from Magnolia and Bear's foot," Pharmacology Biochemistry and Behavior, vol. 79, no. 2, pp. 299-302, 2004. 


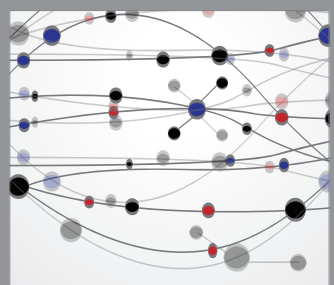

The Scientific World Journal
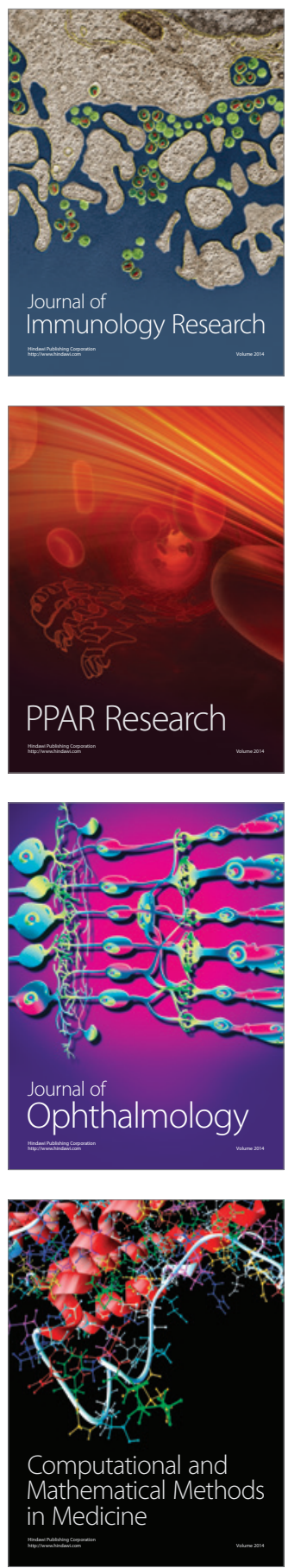

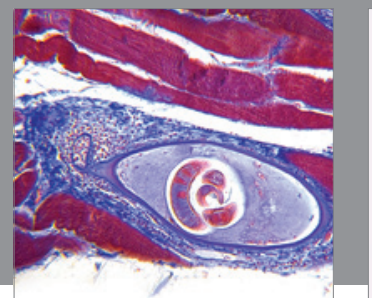

Gastroenterology

Research and Practice
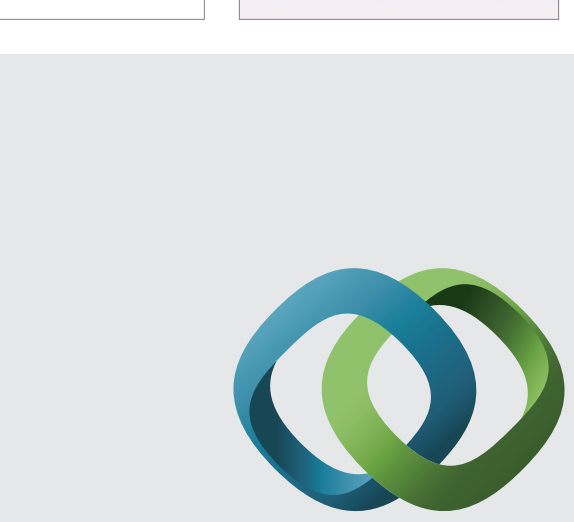

\section{Hindawi}

Submit your manuscripts at

http://www.hindawi.com
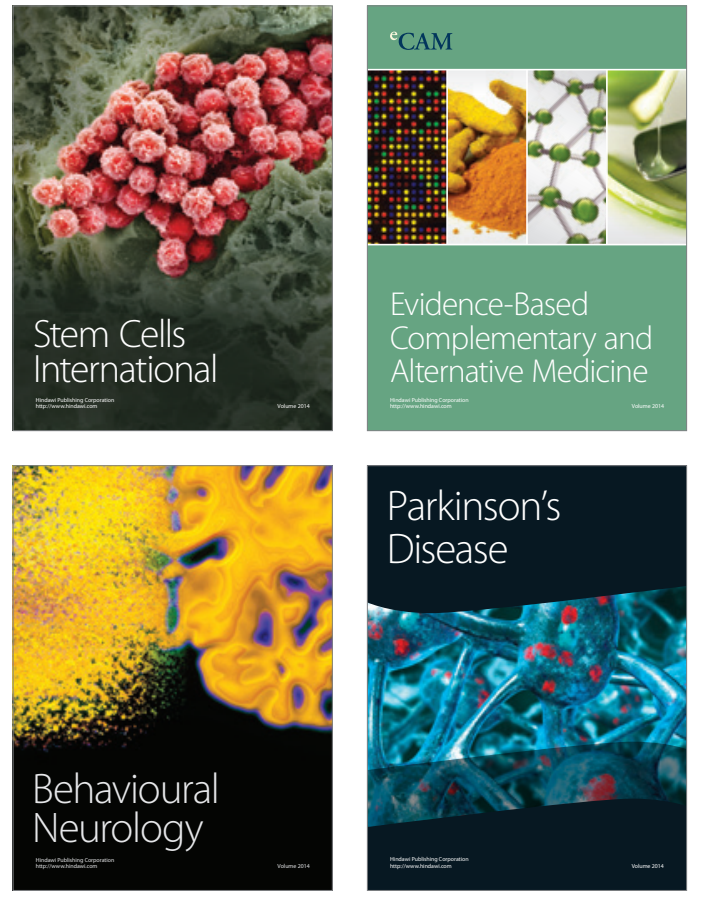
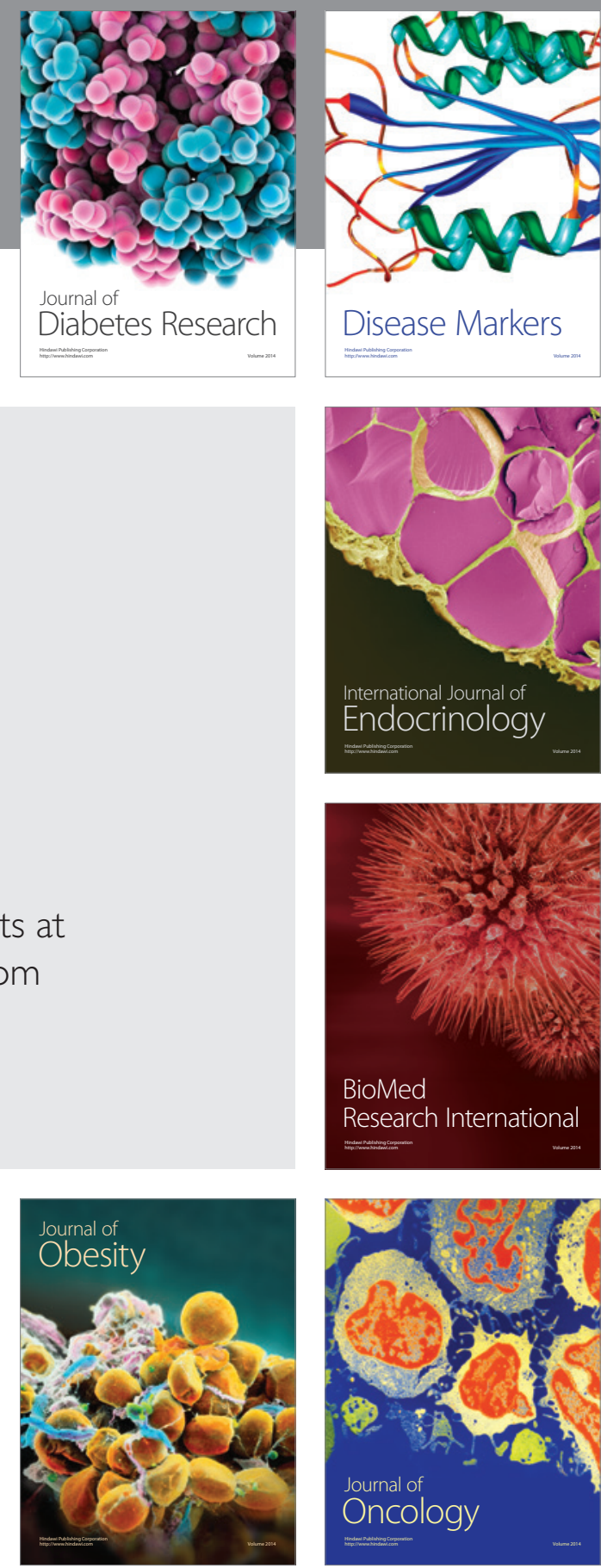

Disease Markers
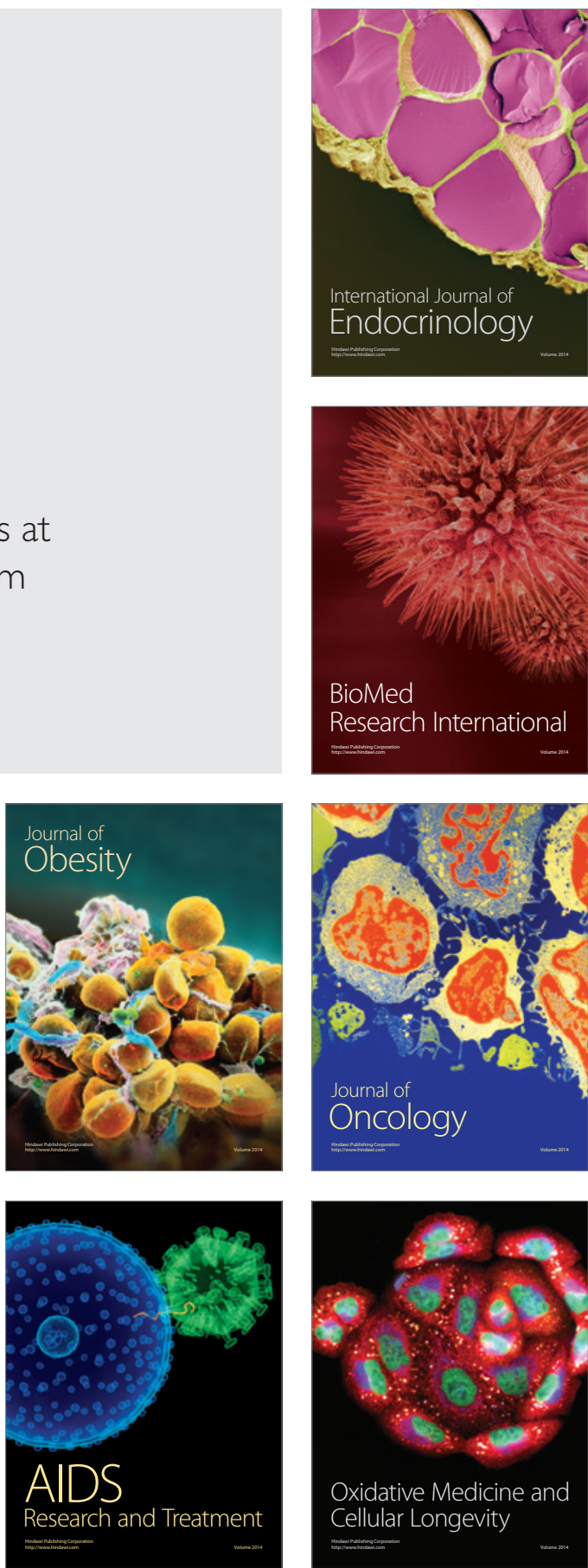